\title{
LIVRO DIDÁTICO INOVADOR E PROFESSORES: UMA TENSÃO A SER VENCIDA ${ }^{1}$ INNOVATING TEXTBOOK AND TEACHERS: A CHALLENGE TENSION
}

\author{
Maria Helena da Silva Carneiro \\ Faculdade de Educação - Universidade de Brasília \\ mhsilcar@unb.br \\ Wildson Luiz Pereira dos Santos \\ Gerson de Souza Mól \\ Instituto de Química - Universidade de Brasília \\ wildson@unb.br-gmol@unb.br
}

\section{Resumo}

A adoção de livros didáticos de Ciências que incorporem abordagens metodológicas inovadoras pode contribuir para mudanças na prática docente. O objetivo deste artigo é discutir a função pedagógica do livro didático e sua relação com o professor e analisar concepções de um grupo de professores que adotou um livro didático inovador a respeito das características que eles identificam nesse livro. A análise dessas concepções evidencia uma tensão entre o anseio de adotar mudanças de estratégias indicadas pelo livro didático e as dificuldades de desenvolver práticas diferenciadas das convencionais. Essa tensão leva os professores à, contraditoriamente, apontarem aspectos inovadores do livro, tanto de forma positiva como de forma negativa. Reflexões relativas à formação de professores são discutidas ao final do artigo.

Palavras-chave: livro didático, ensino de Química, formação de professores.

\section{Abstract}

The adoption of innovating science textbooks that incorporated new methodology approaching can contribute for changing in science classrooms. In this paper, we discuss the pedagogic role of these textbooks and their relation with teachers; and we present the analysis of the conceptions of teachers on an innovation textbook for showing how they identify the innovation textbook features. For this, the conceptions of chemistry teachers who have adopted an innovation textbook since the beginning of the year are discussed. The analysis of the teachers' views shows a tension between the teachers' intentions to adopt the new strategies indicated by textbook and some difficulties to develop the new practices. Reflections on the training teachers are discussed in the end of the paper.

Key words: textbook, chemistry teaching, teacher training.

\footnotetext{
${ }^{1}$ Uma versão preliminar deste artigo foi apresentada em sessão de comunicação oral no IV Encontro Nacional de Pesquisa em Educação em Ciências, Associação Brasileira de Pesquisa em Educação em Ciências, Abrapec, Bauru SP, nov. 2003.
} 


\section{Introdução}

Apesar dos avanços tecnológicos e da enorme variedade de materiais curriculares, atualmente disponíveis no mercado, o livro didático, LD, continua sendo o recurso mais utilizado no ensino de ciências. Essa centralidade lhe confere estatuto e funções privilegiadas na medida em que é através dele que o professor organiza, desenvolve e avalia seu trabalho pedagógico de sala de aula. Para o aluno, o livro é um dos elementos determinantes da sua relação com a disciplina. Como afirma Santomé (1998), a lembrança que grande parte das pessoas tem de disciplinas cursadas está relacionada a livros didáticos, particularmente os de Matemática, Física e Química. Essa peculiaridade também condicionará suas avaliações, expectativas e interesses por essas áreas do conhecimento. $\mathrm{O}$ autor nos lembra ainda que não é raro encontrar pessoas que, devido a "fracassos" nessas disciplinas durante o período de escolarização, passem a considerar-se incapazes de compreender seus conhecimentos, chegando a mitificar e supervalorizar aqueles que compreendem os conceitos científicos. Portanto, é indubitável a marca que o LD deixa na vida dos alunos.

A investigação sobre LD não se caracteriza como um campo novo. Nas últimas décadas, ele foi objeto de várias pesquisas (Freitag, Costa e Mota, 1989; Höffling, 2000; Pretto, 1985). A tendência maior desses trabalhos recai, normalmente, sobre a análise de seus conteúdos, visando identificar prováveis erros conceituais, ideologias por eles veiculadas, concepções de ciências adotadas, sua evolução histórica e as Políticas do Ministério da Educação, enquanto seu principal "consumidor". No entanto, alguns aspectos têm ficado à margem desses estudos como, por exemplo, a análise da proposta metodológica, as relações entre esse recurso de ensino e as práticas pedagógicas do professor e, finalmente, há ainda poucos estudos sobre suas diferentes formas de uso no contexto escolar.

Ferreira e Selles (2003) identificaram dezessete artigos sobre livros didáticos de Ciências, LDC, que foram veiculados em periódicos nacionais desde a década de 1980. Essas autoras constataram que a maioria dos artigos se dedica a aspectos conceituais apresentados nos livros didáticos de Ciências. $\mathrm{Na}$ análise que desenvolveram, as autoras classificam os artigos em três categorias analíticas. O primeiro grupo de trabalhos apresenta o foco na detecção de erros conceituais. O segundo grupo de artigos toma os erros conceituais como referencial para 0 desenvolvimento de suas análises, embora a detecção desses erros não tenha sido o objetivo principal do trabalho. Finalmente, a terceira categoria analítica apresenta como preocupação central o modo como os livros abordam aspectos relacionados à natureza da ciência.

No caso de livros didáticos de Química, LDQ, além dos artigos analisados por Ferreira e Selles (2003), algumas dissertações de Mestrado foram desenvolvidas como o foco nessa temática. A primeira delas foi a de Schnetzler (1980) que analisa o tratamento do conhecimento químico veiculado por livros didáticos de Química publicados no Brasil durante o período de 18751978. Considerando a impossibilidade de analisar todo o conteúdo apresentado durante este período, a autora optou por analisar o tema reações químicas, uma vez que esse se fazia presente em todos os 28 livros em estudo. Após análise minuciosa do tema em questão, utilizando parâmetros bem definidos, a autora conclui que

[...] além dos livros analisados não se caracterizarem por enfatizar a experimentação e o relacionamento da química com a vida cotidiana, a insignificante presença de tais parâmetros associados à ênfase de propiciar a ocorrência de aprendizagem significativa decrescem com o passar dos anos. (p. 123). 
Schnetzler (1981) destaca também como os livros didáticos

refletem que o ensino secundário de química brasileiro (durante o período analisado) tem sido eminentemente teórico, centrado na veiculação de conhecimentos dissociados da sua própria natureza experimental, negligenciando, desta forma, o seu caráter investigativo, a sua importante aplicação à sociedade e, conseqüentemente, a sua potencialidade para desenvolver espírito crítico nos alunos. Além disso, os resultados indicam que tais características têm se acentuado com o passar dos anos. (p. 15).

Outra dissertação nessa linha foi desenvolvida por Mortimer (1988). Nela o autor analisa a evolução dos LDQ, destacando suas principais características, em cada um dos cinco períodos estudados, em relação à seleção e organização dos conteúdos, à apresentação gráfica e às atividades propostas. Uma das conclusões de Mortimer (1988) é que, ao longo da história, os autores de LD têm dificuldades em inovar, ou seja, romper com certas tradições. Na verdade, as únicas rupturas que ele constatou foram "as relacionadas à apresentação dos livros didáticos e à posição dos temas que se está discutindo no programa de segundo grau" (p. 39). Segundo o autor, todos os livros analisados apresentam problemas relativos à desatualização e à simplificação dos conteúdos químicos.

Lopes (1990, 1993) analisou em sua dissertação os LDQ mais utilizados no Brasil, durante o período de 1931 e 1990. Usando a categoria bachelardiana de obstáculo epistemológico, a autora investigou como se situa epistemologicamente o conteúdo químico transmitido em nossas escolas por meio de livros didáticos. Esse estudo nos apresenta também um histórico do ensino desta disciplina no Brasil. Lopes (1990) conclui que

o apelo às imagens fáceis, capazes de permitir ao aluno associação imediata com idéias que Ihes são familiares, mostra-se então como caminho preferido dos livros didáticos. Não há problematização dos conceitos, nem tampouco o desenvolvimento do raciocínio dos alunos. Mais uma vez o objetivo alcançado é a consolidação do senso comum. (p. 260).

Em sua dissertação, Botár (1994) analisou as opiniões de alunos sobre o LDQ e concluiu que para eles, "o livro importante é aquele que leva em conta a questão da aprendizagem significativa por meio de uma 'pedagogia do esforço e do prazer' propiciando desafios mais elevados que os que geralmente são oferecidos pelos livros atuais" (p. 97). Botár (1994) destaca, que

os estudantes não excluem a praticidade deste livro, que não necessita ser obrigatoriamente volume único. É preferível que venha dividido em um pequeno, para consultas rápidas e um outro, para referências. É importante também que todos tenham alcance aos dois tipos de livro. ( $p$. 97).

Apesar das várias pesquisas sobre LD, LDC e LDQ, ainda são inexpressivos os estudos que se ocupam do cotidiano do livro didático na sala de aula ou das concepções dos usuários professores e alunos - a respeito desse material curricular. Neto e Fracalanza (2003) citam pesquisa realizada com professores de Ciências nas quais foram analisadas concepções e práticas de professores sobre o livro didático de Ciências e sobre critérios utilizados para seleção dos mesmos. Segundo esses autores, os professores foram classificados em três grupos de acordo com as formas pelas quais utilizam o livro didático em suas atividades docentes: fonte 
para planejar e preparar suas aulas; apoio às atividades de ensino-aprendizagem; ou fonte bibliográfica. Ainda segundo os autores, os critérios que os professores afirmam estabelecer para analisar e avaliar coleções didáticas praticamente são os mesmos adotados pelo Ministério da Educação. Cassab e Martins (2003) investigaram os sentidos que professores atribuem ao livro didático numa situação de escolha do material e concluíram que esses são plurais e se relacionam com as suas representações de aluno, de ensino-aprendizagem e de professor.

Com o objetivo de avaliar como livros didáticos inovadores podem influenciar professores de Ciências e suas práticas pedagógicas, estamos desenvolvendo um amplo projeto de pesquisa no qual o presente trabalho se insere. Foi selecionado o módulo um da coleção de Química da editora Nova Geração, destinada ao ensino médio, como primeiro a ser analisado, considerando o seu caráter inovador em diversos aspectos e o nosso interesse em compreender seu impacto pedagógico.

No presente trabalho, discutimos a função pedagógica do livro didático - LD - e sua relação com o professor e apresentamos uma análise das concepções de professores a respeito do livro "Química e Sociedade". Dessa forma, buscamos compreender a visão que professores têm desse livro, identificando aspectos positivos e negativos e explicitando os significados que emergem dessas concepções. Entendemos que um maior conhecimento acerca das concepções dos usuários, neste caso professores, a respeito do LD permite avanços que podem propiciar melhorias desse importante recurso de ensino; possibilita a identificação de indicadores que subsidiem o uso do mesmo em sala de aula; e aponta a necessidade de mudanças que poderão ser incorporadas em outros módulos e em novas edições.

\section{O livro didático e o professor}

As críticas aos livros didáticos não são recentes. Bachelard (1996), em 1938, ao se referir aos livros didáticos daquela época, ressalta que os mesmos apresentam

a ciência como ligada a uma teoria geral. Seu caráter orgânico é tão evidente que será difícil pular algum capítulo. Passadas as primeiras páginas, já não resta lugar para o senso comum; nem se ouvem as perguntas do leitor. Amigo leitor será substituído pela severa advertência: preste atenção, aluno! O livro formula as suas próprias perguntas. O livro comanda. (p. 31).

Continuando sua análise crítica, Bachelard (1996), ao comparar os livros didáticos do século XX com um livro do século XVIII, destaca o distanciamento que existe entre a forma de apresentação dos conteúdos e o cotidiano do leitor:

Peguem um livro científico do século XVIII e vejam como está inserido na vida cotidiana. $O$ autor dialoga com o leitor como um conferencista. Adota os interesses e as preocupações naturais. Por exemplo: quer alguém falar de trovão? Começa-se por falar com o leitor sobre o medo do trovão, vaise mostrando que esse medo não tem razão de ser, repete-se mais uma vez que, quando o trovão reboa o perigo já passou, que só o raio pode matar. (p. 31).

Zabala (1998) fez um levantamento das principais críticas a esse recurso de ensino. Dentre as apresentadas, destacamos: tratamento unidirecional dos conteúdos, dogmatismo e apresentação dos conhecimentos como prontos e sem possibilidade de questionamento. Merece destaque também o fato de os LD não potencializarem a investigação nem o contraste entre a 
educação escolar e a realidade extra-escolar, dificultando a formação de atitude crítica do aluno.

Uma das críticas mais contundentes ao LD é que ele impõe ao professor, não somente os conteúdos a serem trabalhados, como também um conjunto de procedimentos que se cristaliza na sala de aula, condicionando seu trabalho. Todavia, isso precisa ser repensado, uma vez que trabalhos mais recentes, como o de Nascimento (2002), demonstram que os professores, durante o processo de organização, desenvolvimento e avaliação do trabalho pedagógico, usam uma variedade de LD e de outros materiais, tais como revistas de divulgação científica e livros paradidáticos. Na verdade, eles utilizam livro(s) como outros profissionais utilizam recursos relacionados à sua prática. Afinal, subsidiar o trabalho pedagógico do professor não é uma das funções do LD?

Richaudeau (1979), antes de discutir as funções do LD, indica três formas de análise, a partir de seus objetivos gerais ou de seu funcionamento pedagógico. Quanto à primeira forma, três perspectivas nos são apresentadas. Do ponto de vista científico, o LD apresenta não somente os conhecimentos, mas, através deles, toda uma ideologia a ele relacionada. Isso não poderia ser diferente, pois, independente da forma de apresentação dos conhecimentos científicos, sempre estará presente, por exemplo, uma concepção de ciência. Do ponto de vista pedagógico, o LD reflete uma concepção de comunicação e de aprendizagem. O terceiro aspecto destacado pelo autor refere-se ao uso institucional desse recurso de ensino, por estar relacionado à organização e hierarquização do sistema escolar, a divisão dos conhecimentos em disciplinas e a definição de programas.

Considerando o papel pedagógico do LD, concordamos com Richaudeau (1979) quando destaca que o LD apresenta três grandes funções. A primeira é a função de informação e todas as implicações que dela advêm. A segunda função é a de estruturação e organização da aprendizagem dos estudantes. A última função, considerando que o livro didático não pode ser por si mesmo um fim, é a de guiar os alunos em sua apreensão do mundo exterior, em colaboração com outros conhecimentos adquiridos em outros contextos distintos do escolar.

Nesse sentido, é natural que o professor continue usando extensivamente o livro didático. Zabala (1998) tece algumas considerações interessantes a respeito:

Nossa tarefa prioritária como educadores não consiste na confecção de materiais que devem nos ajudar a desenvolver as atividades educativas. $A$ tarefa de ensinar envolve ter presente uma quantidade enorme de varáveis, entre elas as que nos indicam as necessidades particulares de cada menino e menina e de selecionar as atividades e os meios que cada um deles necessita (...). O fato de ter que utilizar materiais elaborados por outros não significa uma dependência total, nem a incapacidade de confeccionar os materiais necessários quando a oferta do mercado não se ajusta às necessidades que queremos atender. (p. 176).

Portanto a questão sobre o livro não deve ser colocada de forma radicalizada, mas em termos do uso que se faz desse tipo de material curricular. Por exemplo, um livro considerado ruim pode ser um excelente ponto de partida para as discussões desenvolvidas em sala de aula.

Minimizar os danos do mau livro começa pela atividade de que precisa preceder o uso de qualquer livro didático, bom ou ruim, voluntariamente escolhido ou autoritariamente imposto: leitura integral e atenta do livro, de capa a capa, da folha de rosto até a última página (...). Trabalhar em classe com um livro inadequado exige excepcional firmeza. Serão vários os momentos e situações em que o professor precisará dizer à classe que o livro merece ressalvas, que o que o livro diz não está certo. A segurança 
com que o professor vai dizer aos alunos que, ao contrário do que se lê no livro didático, casa se grafa com s e não com z, ou que o Presidente da República em março de 1964 não era Jânio Quadros, mas João Goulart, dá um tom de discussão com os alunos dos limites da infalibilidade dos saberes. Professores e alunos, nesta situação, vivem coletivamente uma experiência que ensina que nem todos os livros estão sempre certos sobre tudo, que em várias situações é preciso ir além do que diz o livro, e que na situação de sala de aula o professor é o mais qualificado para referendar ou não o que está no livro. (Lajolo, 1996, p. 6).

Nessa mesma direção, Freitag, Costa e Mota (1989) afirmam que:

Os estudos até agora realizados sobre o livro didático deveriam ser intensificados, focalizando-se, antes de mais nada, o como de sua utilização pelo professor no quotidiano da sala de aula. Haveria inúmeras possibilidades de um bom professor, usando um mau livro didático, desenvolver um excelente ensino e promover um extraordinário aprendizado. Por enquanto, o uso feito pelo professor somente foi estudado na perspectiva dos critérios utilizados pelo professor para a escolha do livro. (p. 125).

Assim, qualquer material didático poderia ser utilizado durante as atividades de sala de aula, desde que o professor tenha consciência dos "problemas" nele existentes e os discuta com os alunos.

\section{Procedimentos metodológicos}

O projeto de pesquisa no qual este trabalho se insere compreende várias etapas de investigação: aplicação de questionários e entrevistas semi-estruturada com professores, entrevista com alunos e gravação em vídeo de aulas. Neste artigo estamos apresentando a análise das concepções dos professores manifestadas nos questionários que foram aplicados ao término do primeiro semestre de 2003. Foram selecionados professores que utilizaram o livro "Química e Sociedade" (Mól e Santos, 2003) como livro texto em suas classes.

Foram elaborados dois questionários: um de dados sociobiográficos e outro sobre a avaliação do professor em relação ao livro "Química e Sociedade".

O primeiro questionário tinha como objetivo delinear o perfil profissional do professor em termos de sua formação acadêmica (inicial e continuada), dados da escola onde trabalha e sua relação com o livro didático.

O segundo questionário continha perguntas sobre aspectos positivos e negativos que 0 professor identificou no Guia do Professor, que acompanha o livro, e critérios utilizados para escolha do livro. Outras perguntas solicitavam avaliação, em escala de 1 a 5, com solicitação de justificativas, dos seguintes parâmetros: ilustrações, adequação da linguagem para os alunos, atualização conceitual, organização e coerência dos conteúdos, adequação do conteúdo para os alunos, apresentação dos conceitos químicos fundamentais, abordagem temática, facilitação da aprendizagem dos conhecimentos químicos, abordagem experimental, diversidade de atividades, adequação dos exercícios aos alunos, quantidade de exercícios para avaliar a compreensão dos textos, desenvolvimento de valores socioculturais e espaço para que o professor apontasse outros aspectos que desejasse acrescentar; os aspectos positivos e as dificuldades no uso do livro em sala de aula; e os aspectos positivos e negativos que têm sido comentados pelos alunos 
a respeito do livro.

No Distrito Federal, em 2003, cerca de dez professores adotaram o livro segundo informações fornecidas pelo distribuidor. Desses, oito professores responderam ao questionário que foi aplicado por um aluno de iniciação científica. O aluno agendou previamente a entrevista, orientou os professores para que apresentassem suas opiniões ao avaliar cada parâmetro de análise do livro e acompanhou-os durante as respostas às questões. Todos os dados foram tabulados e para sua análise, na busca de identificação das concepções, foram levadas em conta as informações de campo registradas pelo aplicador e os dados sociobiográficos dos professores.

\section{Caracterização do livro estudado}

A coleção de Química da editora Nova Geração está sendo produzida pelo grupo de professores do Projeto de Ensino de Química e Sociedade - PEQUIS ${ }^{2}$-, que é desenvolvido no Laboratório de Pesquisas em Ensino de Química do Instituto de Química da Universidade de Brasília. Os livros desta coleção, "Química e Sociedade", têm como proposta explícita a abordagem de temas sociais, visando preparar o aluno para o exercício consciente da cidadania, por meio do conhecimento de conceitos químicos básicos e das implicações sociais da Química. O livro é acompanhado pelo "Guia do Professor", no qual os autores o apresentam como resultado de um projeto que busca incorporar inovações apontadas pelas pesquisas em ensino de Química. A coleção é dividida em nove módulos que englobam todo o conteúdo do ensino médio, sendo que cada módulo trata de um tema social, denominado tema em foco, que é abordado ao longo de seus capítulos. Em janeiro de 2003, foi publicado o módulo 1: Química e Sociedade - a ciência, os materiais e lixo (Mól e Santos, 2003). Já foram publicados quatro módulos e os demais estão em processo de produção.

Além da contextualização social que caracteriza sua abordagem, a obra apresenta outros aspectos inovadores: a inclusão de diversas atividades de construção do conhecimento, muitas das quais envolvendo experimentos investigativos; a abordagem contextualizada dos conceitos químicos; o redimensionamento do conteúdo químico; além de um formato editorial rico em ilustrações vinculadas aos temas abordados. Essas características o diferenciam dos demais livros disponíveis no mercado, conferindo-lhe um caráter inovador, tanto no que diz respeito à forma de apresentação dos conteúdos, quanto à abordagem metodológica e ao formato.

\section{Resultados e discussões}

Dos oito professores que responderam aos questionários, todos possuem licenciatura plena em Química, sendo três em universidade particular e cinco em universidade pública. A maioria tem mais de sete anos de magistério. Portanto, são professores considerados com certa experiência no ensino de Química. A análise das respostas dadas pelos professores entrevistados permitiu-nos fazer a uma série de constatações.

Com relação ao Guia do Professor, foram destacados, entre outros, os seguintes aspectos positivos: atualidade dos temas, diversidade das atividades propostas, coerência com os Parâmetros Curriculares Nacionais - PCN. Foram apresentados os seguintes aspectos negativos: "pouca teoria evidenciada nos textos" e pouca sugestão de atividades extras.

O fato de o livro apresentar temas atuais é importante, uma vez que não resta dúvida de

\footnotetext{
${ }^{2}$ O PEQUIS é um projeto no qual seis professores do ensino médio participam do processo de elaboração, aplicação e avaliação de materiais didáticos. Já foram produzidas duas versões do livro "Química na Sociedade" (Mól e Santos, 1998 e 2000), publicados pela editora da Universidade de Brasília.
} 
que os livros didáticos, além de apresentarem os conceitos básicos da disciplina, devem também apresentar outros temas que evidenciem a dinâmica da construção do conhecimento científico e possibilitem o desenvolvimento de atitudes e valores relacionados à cidadania (Santos e Mortimer, 2000; Santos e Schnetzler, 1997).

No que se refere à diversidade das atividades propostas, percebe-se uma divergência de opiniões. Essa é compreensível visto que as concepções a respeito do livro didático variam de acordo com a experiência e a formação geral de cada um. Percebe-se, contudo, que o grupo de professores entrevistados concebe que o guia do professor não deve ser caracterizado como apenas uma cópia do LD do aluno acrescida de respostas dos exercícios. Isso evidencia a importância de que o guia do professor apresente sugestões de atividades, considerando que as condições de trabalho do professor que, geralmente, são de quarenta horas semanais, sem tempo para leituras complementares ou realização de cursos de formação continuada. Esse suporte pedagógico aos professores, presente no guia em análise, tanto foi reconhecido como importante, como ainda foi considerado insuficiente por um dos docentes. Deve-se destacar que esse professor que solicitou a sugestão de maior quantidade de atividades é um dos que está constantemente participando de cursos de formação continuada.

Como ressalta Lajolo (1996),

O livro do professor precisa interagir com seu leitor-professor não como a mercadoria dialoga com seus consumidores, mas como dialogam aliados na construção de um objetivo comum: ambos, professores e livros didáticos, são parceiros em um processo de ensino muito especial, cujo beneficiário final é aluno.

Esse diálogo entre livro didático e professor só se instaura de forma conveniente quando o livro do professor se transforma no espaço onde o autor põe as cartas na mesa, explicitando suas concepções de educação, as teorias que fundamentam a disciplina de que se ocupa seu livro. (p. 4).

Outro aspecto interessante a ser ressaltado é que um dos professores considerou positiva a coerência entre o guia e os PCN (Brasil, 1999). Apesar da proposta metodológica inicial do livro ter sido desenvolvida antes da publicação dos PCN, no guia do professor da versão atual, há menção, em vários momentos de pressupostos desses parâmetros. Entre outros, podemos destacar a contextualização social do conhecimento químico e o redimensionamento dos conteúdos abordados. Os comentários apresentados pelos professores sobre os PCN são indícios de que, de certa forma, as orientações oficiais acabam influenciando o discurso dos mesmos.

Com relação ao uso do livro do aluno em sala de aula, os aspectos positivos apontados por mais de um dos professores foram os seguintes: diversidade de temas relacionados ao cotidiano do aluno, a estrutura física do livro e a sua linguagem. Já em relação aos aspectos negativos, apenas a forma de abordagem dos conceitos foi apontada por mais de um professor.

Segundo os professores, os alunos apontaram os seguintes aspectos positivos: ilustrações atrativas, formato de revista, temas e experimentos simples. Os seguintes negativos apresentados foram: temas repetitivos, fragilidade do livro e pequena quantidade de exercícios.

Quanto às ilustrações foram destacadas a quantidade e a sua pertinência. Dois destacam que as mesmas "são significativas, mas estão em excesso". O instrumento não nos permite analisar o que seria para esses professores "imagens significativas...", mas podemos inferir que para os mesmos, a imagem desempenha um papel pedagógico no ensino de Química. Isso pode ser destacado, pois a qualidade das imagens foi um dos aspectos mais mencionados 
como positivos, tanto pelos professores, como pelos alunos.

Quatro professores analisam as ilustrações do ponto de vista da sua relação com o texto. Podemos inferir que, para esse grupo de professores, as imagens do LD têm como função primordial ilustrar um texto ("fotos condizentes com os textos"), ou seja, ser redundante ao conteúdo explicado pela linguagem escrita, não evidenciando assim outras funções pertinentes às imagens em livros didáticos.

Quanto à linguagem, percebe-se que não há um consenso por parte dos professores. Enquanto três destacam o estilo de linguagem adotado pelo livro como um aspecto que dificulta a aprendizagem do aluno, outros quatro ressaltam essa mesma característica como elemento facilitador. Essa opinião não consensual ficou expressa também nos comentários dos professores sobre os aspectos positivos e negativos do livro. Por exemplo, para um dos professores "o aluno não consegue assimilar a teoria dentro dos textos", mas para outro "os alunos conseguem compreender claramente o texto". Esse antagonismo pode ser justificado pelo fato de que no livro "Química e Sociedade" os conceitos são apresentados a partir de textos dissertativos mais desenvolvidos que buscam criar condições para favorecer o estabelecimento de relações conceituais que facilitem a sua aprendizagem, quer a partir de observações fenomenológicas, de sua relevância sócio-tecnológica, ou de seu contexto histórico; enquanto os livros convencionais (aprovados pelo uso) geralmente apresentam diretamente os conceitos por meio de diagramas, esquemas, exemplos com poucos textos explicativos e até mesmo algumas vezes sem defini-los. Tanto os alunos como os professores estão acostumados com um registro discursivo específico dos LD, geralmente por meio de textos diretos e esquemáticos, e a uma única organização lógica dos conteúdos, já historicamente padronizados. Assim, é natural o estranhamento ao se depararem com uma abordagem diferente, gerando tensão no processo de adoção de novas propostas metodológicas.

Seis professores pontuam com nota máxima (cinco) e um com nota quatro a atualização conceitual do livro. Segundo um deles, "o livro supera a abordagem que alguns ainda mantêm, mesmo quando errados". Isso pode ser um indício de que, para esses professores, a presença de conhecimentos atuais é uma característica importante do livro. Deve-se destacar aqui que LDQ convencionais muitas vezes apresentam conceitos químicos com terminologia imprecisa ou que pode gerar dificuldades de aprendizagem (Lopes, 1994; Mortimer, 1988), como a classificação de misturas heterogêneas (Silva, Rocha-Filho, Tunes, e Tolentino, 1986) ou a definição de substâncias a partir do conceito de moléculas. Levando-se em consideração a opinião dos professores, no que diz respeito a atualização conceitual, podemos, portanto, inferir que os mesmos consideram importante que definições desatualizadas e consagradas nos LDQ sejam revistas, com já apontava Mortimer (1988).

Quanto à organização e coerência dos conteúdos, observa-se um dissenso entre as opiniões. Um professor atribuiu nota mínima e dois deles atribuíram nota 3 alegando que a "seqüência lógica dos conteúdos" e a "relação entre tema e conteúdo" não são boas. Enquanto cinco professores avaliaram com nota quatro e cinco esse parâmetro. Para um desses, o livro apresenta "conteúdos seqüenciais bem ligados, o que facilita uma abordagem em espiral". Esse dissenso pode ser compreendido, pois é difícil romper com a organização dos conteúdos que impera nos livros didáticos mais utilizados, que orientam o trabalho dos professores, fato que leva a uma resistência às propostas inovadoras. Enquanto há essa dificuldade para muitos professores, outros já começam a reconhecer a necessidade de mudança da organização lógica dos conteúdos que tem sido apontada pelos pesquisadores da área de ensino de Química (Brasil, 1999; Mortimer, Machado e Romanelli, 2000).

De acordo com os professores, no que se refere à adequação do conteúdo para os alunos, a maioria avaliou positivamente: "o conteúdo é de fácil assimilação e interpretação para 
os alunos". Essa avaliação é confirmada no parâmetro sobre facilitação da aprendizagem dos conhecimentos químicos, na medida em que a maioria dos professores também atribui notas superiores a esse aspecto. Outros parâmetros avaliados positivamente pelos professores foram os relativos às abordagens temática e experimental. Como destaca um dos professores os "temas apresentados do cotidiano que desenvolvem no aluno a capacidade que o mesmo possui de refletir e debater com os colegas e professores"; e como menciona outro "os experimentos propostos estão de acordo com o tema / conteúdo e podem ser realizados".

Enquanto os professores manifestaram uma boa aceitação em relação à adequação do conteúdo, à facilitação da aprendizagem e às abordagens temática e experimental, por outro lado, demonstraram certo desconforto em relação às atividades propostas. Nos parâmetros: diversidade de atividades, adequação dos exercícios aos alunos e quantidade de exercícios para avaliar a compreensão dos textos, apesar de os professores, na sua maioria, atribuírem notas mais elevadas, eles fizeram ressalvas como: falta de mais exercícios envolvendo cálculos e inadequação do livro em preparar os alunos para a resolução de exercícios de vestibular. Mais uma vez, pode-se observar aqui a resistência de adoção de materiais inovadores, por suas atividades diferirem do padrão convencional de exercícios estilizados, próprios de vestibulares.

$\mathrm{Na}$ avaliação da diversidade de atividades proposta no livro, os professores também atribuíram uma nota avaliativa da média para cima. Entretanto, pode-se observar certo desencontro de opiniões nas justificativas apresentadas. Enquanto um professor afirmou que há necessidade de "mais exercícios envolvendo cálculos", para outro o livro apresenta "atividades suficientes para desenvolver e construir o conhecimento". Sobre a quantidade de exercícios para avaliar a compreensão dos textos um professor atribuiu nota média enquanto os demais avaliaram bem, indicando certa harmonia na avaliação.

O penúltimo item, relacionado ao desenvolvimento de valores socioculturais, obteve uma nota média e as demais foram altas. Essa avaliação positiva é condizente com uma das características da coleção que tem como uma de suas propostas o estímulo ao desenvolvimento de valores, a partir do estudo de conceitos científicos. Segundo os professores, o uso de tema permite "despertar nos alunos a noção de cidadania" e contribui para que os alunos "amadureçam e compreendam a dura realidade de nosso povo".

A avaliação do formato diferenciado do livro não é consensual, agradando alguns e desagradando a outros. Aqui, mais uma vez percebe-se que mudanças no padrão do LD geram alguma resistência.

\section{Considerações finais}

A análise das concepções dos professores sobre o livro "Química e Sociedade" evidenciou a existência de uma tensão entre a vontade dos professores em adotar mudanças de estratégias indicadas pelo referido livro e as dificuldades em desenvolver práticas diferenciadas das convencionais. Conforme pôde-se observar, os professores ora apresentavam aspectos inovadores LDQ como positivos e ora os consideravam como aspectos negativos. Isso nos indica que mudanças educacionais dependem não somente da aceitação de novas propostas, mas do desenvolvimento de novas práticas para as quais os professores se sintam seguros.

Pode-se destacar que a análise feita evidenciou que os professores manifestaram um maior incômodo com a mudança na organização dos conteúdos e com o formato dos exercícios. Por outro lado, os aspectos mais apreciados pelos docentes foram a abordagem temática, o fato de os temas serem atuais e relacionados ao cotidiano do aluno, a adequação do conteúdo, a facilitação da aprendizagem, a abordagem experimental e, finalmente, o fato de o livro ser bem ilustrado. Isso, de certa forma, evidencia que os professores reconhecem a necessidade de 
inovação em termos metodológicos. Todavia, parece que a pressão dos vestibulares sobre o ensino médio tem ainda um grande peso na resistência de professores às mudanças propostas.

Outra reflexão que pode ser levantada diz respeito ao papel do LD nas mudanças curriculares. No seu cotidiano, o professor se depara com uma série de exigências burocráticas e pedagógicas. Quanto às exigências pedagógicas, o professor tem que prever, organizar e articular as atividades que serão desenvolvidas no contexto escolar. Dessa forma, com pouco tempo para planejamento, o professor se sente seguro ao seguir os roteiros didáticos já estabelecidos nos livros convencionais. Nesse sentido, a existência de livros que tragam novas propostas metodológicas tem um papel fundamental como apoio ao professor e, nesse contexto, torna-se necessária a formatação de novos Guias do Professor que possam contribuir de maneira mais significativa, não se restringindo à exposição de modelos de resolução de exercícios.

Assim sendo, defendemos a tese de que o livro didático também pode ser um elemento propiciador de mudanças de práticas pedagógicas ou encorajador da manutenção de metodologias tradicionais, uma vez que esse recurso ainda é muito utilizado por professores e alunos. Pó isso, faz-se necessário que os livros didáticos sejam concebidos a partir de propostas pedagógicas bem definidas e não como apenas um amontoado de conteúdos.

Uma das funções do livro didático é a de dar suporte ao processo de ensinoaprendizagem. No entanto, se conhece muito pouco sobre o cotidiano desse recurso na sala de aula e sobre concepções de professores e alunos a respeito do mesmo. Portanto, faz-se necessário o desenvolvimento de mais pesquisas que se ocupem dos seus usuários, pois, no Brasil, esses trabalhos ainda são muito inexpressivos.

Acreditamos também que o estudo dos livros didáticos pelos professores é altamente formador, pois eles, na sua maioria, têm a ilusão de que já conhecem o LD, visto que os manipulam desde o início da sua escolaridade. Colocar em evidência sua organização interna, reconhecer as prováveis funções das imagens, identificar os códigos de leitura que os leitores mobilizam durante o processo de aprendizagem são, entre outras, atividades que levam o futuro professor a se questionar sobre o papel que o LD desempenha e, assim, avaliar as suas próprias representações a respeito desse material curricular.

Um próximo passo de nossa investigação é analisar a prática do professor em sala de aula ao usar um livro inovador e as concepções dos alunos sobre o livro. Esses estudos visam uma melhor compreensão do processo de apropriação do professor das mudanças curriculares presentes nos livros inovadores e das concepções dos alunos sobre o conhecimento químico abordado no livro. Esses estudos vão nos apontar importantes aspectos a serem observados no processo de formação de professores, de mudança curricular e de produção de livro didático. Acreditamos que o livro didático inovador tem um papel fundamental nas mudanças no processo educacional, mas, todavia, compreendemos que o êxito dessas mudanças passa por uma compreensão do trabalho do professor em sala de aula, pois não haverá mudanças enquanto os professores não aceitarem o desafio de mudar sua forma de trabalho. Caso contrário, os livros inovadores podem estar fadados ao fracasso, pois os professores podem não se sentir à vontade para enveredar em novas propostas de trabalho. 


\section{Referências bibliográficas}

BACHELARD, G (1938). A formação do espírito científico. Rio de Janeiro: Contraponto, 1996.

BOTÁR, E. M. Livros didáticos de Química - uma análise das percepções dos estudantes. Brasília, Dissertação (Mestrado em Educação) - Faculdade de Educação da Universidade de Brasília, 1995.

BRASIL, Ministério da Educação, Secretaria do Ensino Médio. Parâmetros Curriculares Nacionais. Brasília, 1999.

CASSAB, M.; MARTINS, I. A escolha do livro didático em questão. In: Encontro Nacional de Pesquisa em Educação em Ciência, IV, 2003, Bauru. Anais... Bauru, 2003. 1. CD-ROM.

FERREIRA, M. S.; SELLES, S. E. A produção acadêmica brasileira sobre livros didáticos em ciências: uma análise em periódicos nacionais. In: Encontro Nacional de Pesquisa em Educação em Ciência, IV, 2003, Bauru. Anais... Bauru, 2003. 1. CD-ROM.

FREITAG, B.; COSTA, W. F.; MOTA, R. V. O livro didático em questão. São Paulo: Cortez, 1989. HÖFFLING, E. M. Notas para discussão quanto à implementação de programas de governo: em foco o Programa Nacional do Livro Didático. Educação e Sociedade, São Paulo, v. 21, n. 70, p. 159-170, abr. 2000.

LAJOLO, M. Livro didático: um (quase) manual de usuário. Em Aberto, Brasília, ano 16, № 69, jan/mar, 1996.

LOPES, A. R. C. Livros didáticos: obstáculo ao aprendizado da ciência Química. Química Nova, v. 15 , n. 3, p. 254-261, 1992.

Livros didáticos: obstáculos ao aprendizado da ciência química. Revista Brasileira de Estudos Pedagógicos, v. 74, n. 177, p. 309-334, maio/ago., 1993.

A concepção de fenômeno no ensino de Química brasileiro através dos livros didáticos. Química Nova, v. 17, n. 4, p. 338-341, 1994.

MÓL, G. de S e SANTOS, W. L. P. dos (coords.); CASTRO, E. N. F de; SILVA, G. de S; MATSUNAGA, R. T.; SILVA, R. R.; FARIAS, S. B.; SANTOS, S. M. de O.; e DIB, S. M. F. Química na Sociedade, módulos 1 e 2. Brasília, Editora da Universidade de Brasília, 1998.

Química na Sociedade, 2 ed. Brasília, Editora da Universidade de Brasília, 2000.

Química e Sociedade: a ciência, os materiais e o lixo, Química: coleção Nova Geração, módulo 1, suplementado com o Guia do Professor. São Paulo, Editora Nova Geração, 2003.

MORTIMER, E. F. A evolução dos livros didáticos de Química destinados ao ensino secundário. Em aberto, ano 7, n.40, p. 25-41, 1988. 
MORTIMER, E. F.; MACHADO, A. H.; ROMANELLI, L. I. A proposta curricular de química do Estado de Minas Gerais: fundamentos e pressupostos. Química Nova, v. 23, n. 2, p. 273-283, 2000.

NASCIMENTO, G. G. O. O livro de Biologia no ensino de biologia. Dissertação de Mestrado. Faculdade de Educação, Universidade de Brasília, 2002.

NETO, J. M.; FRACALANZA, H. O livro didático de ciências: problemas e soluções. Ciência e Educação, v. 9, n. 2, p. 147-157, 2003.

PRETTO, N. de L. A ciência nos livros didáticos. Campinas-SP: Ed. Da Unicamp; Salvador: CED/UFBA, 1985.

RICHAUDEAU, F. Conception et production des manuels scolaires: guide pratique. Paris: UNESCO, 1979.

SANTOMÉ, J. T. Globalização e interdisciplinaridade: o currículo integrado. Porto Alegre: Artes Médicas, 1998.

SANTOS, W. L. P. dos; SCHNETZLER, R. P. Educação em química: compromisso com a cidadania. ljuí, Editora da Unijuí, 1997.

SANTOS, W. L. P. dos; MORTIMER, E. F. Uma análise de pressupostos teóricos da abordagem C-T-S (ciência-tecnologia-sociedade) no contexto da educação brasileira. Ensaio: pesquisa em educação em ciências, v. 2, n. 2, 133-162, dez 2000.

SCHNETZLER, R. P. Um estudo sobre o tratamento do conhecimento químico em livros didáticos brasileiros dirigidos ao ensino secundário de química de 1875 a 1978. Química Nova, v. 4, n. 1, p. 6-15, jan. 1981.

SCHNETZLER, R. P. O tratamento do conhecimento químico em livros didáticos brasileiros para o ensino secundário de Química de 1875 a 1978: análise do capítulo de reações químicas. Campinas, Dissertação (Mestrado em Educação) - Faculdade de Educação da Universidade Estadual de Campinas, 1980.

SILVA, R. R.; ROCHA-FILHO, R. C.; TUNES, E.; TOLENTINO, M. Ensino de conceitos em química: II - Matéria: um sistema conceitual quanto à sua forma de apresentação. Ciência $e$ Cultura, v. 38, n. 12, p. 2028-2030, dez. 1986.

ZABALA, A. A prática educativa. Como ensinar. Porto Alegre: Artes Médicas, 1998. 